\title{
Gradation and Rheological Characteristics of Glacial Debris Flow along the Kangding-Linzhi Section of Sichuan-Tibet Railway
}

\author{
Shuliang Liu $\mathbb{D}^{1},{ }^{1,2}$ Jichun Zhang $\mathbb{D}^{1,2}$ Xie Cheng $\mathbb{D}^{3},{ }^{3}$ Wubin Wang $\mathbb{D}^{1,2}$ \\ and Hongtao Jiang $\mathbb{D D}^{3}$ \\ ${ }^{1}$ Southwest Jiaotong University, Chengdu 611731, China \\ ${ }^{2}$ National Engineering Laboratory for Technology of Geological Disaster Prevention in Land Transportation, \\ Southwest Jiaotong University, Chengdu 611731, China \\ ${ }^{3}$ Sinopec Marketing South China Branch, Guangzhou 510620, China
}

Correspondence should be addressed to Wubin Wang; 15908147006@126.com

Received 5 September 2020; Revised 18 October 2020; Accepted 24 October 2020; Published 19 November 2020

Academic Editor: Chong Xu

Copyright ( 2020 Shuliang Liu et al. This is an open access article distributed under the Creative Commons Attribution License, which permits unrestricted use, distribution, and reproduction in any medium, provided the original work is properly cited.

To date, most research on the characteristics of glacial debris flow along the Sichuan-Tibet railway has focused on numerical simulations and remote sensing, resulting in a lack of direct experimental data from debris flow samples. Therefore, in the present study, a field investigation was conducted along the Sichuan-Tibet railway, and 55 samples of glacial debris flow deposits were systematically analyzed to determine their grading and rheological properties. This is the first systematic experimental study on glacial debris flow deposits. The results showed that the proportion of coarse particles was high and the proportion of fine particles was low in the glacial debris flow along the Sichuan-Tibet railway. The average gravel and sand contents were 37.8\% and 58\%, respectively, and the average contents of silt and clay were $3.7 \%$ and $0.47 \%$, respectively. The average fractal dimension was 2.1507 , which is much greater than that of viscous debris flow. Under the same gravity and shear rate, the stress of typical glacial debris flow was significantly less than that of viscous debris flow, whereas the variability of the stress was more significant. These findings will contribute to revealing the movement rules and disaster risk of glacier debris flow along the Sichuan-Tibet railway and have considerable theoretical and practical significance for ensuring safety during both its construction and later operation.

\section{Introduction}

Debris flow is a natural phenomenon that typically occurs in mountainous and hilly regions. This phenomenon is characterized by a long incubation period, sudden outbreaks, and strong destructive power, is difficult to predict, and typically results in serious casualties [1-4]. Debris flow is an enormous threat to railway construction, particularly in the mountainous and hilly regions of Southwest China, where debris flow frequently occurs. Effective prediction and a comprehensive understanding of the occurrence, characteristics, and damage of debris flow is the key to the successful construction of a railway in a region prone to debris flow.

The Sichuan-Tibet railway, the second railway to be constructed in Tibet, entered a substantive stage of construction in 2014. The Sichuan-Tibet railway will greatly shorten the transportation time between Tibet and developed regions in central and eastern China and will provide important transportation support for regional economic complementarity and resource sharing. The Sichuan-Tibet railway has been described as the most difficult railway in the world to construct because of the extremely steep terrain, with a total climbing height of more than 1400 meters. The construction of the Sichuan-Tibet railway faces considerable geological challenges such as substantial changes in terrain height, strong plate activity (geological fracturing and high-intensity earthquakes), frequent mountain disasters, and a fragile ecosystem.

The construction of the Sichuan-Tibet railway will encounter interference and destruction from various mountain disasters, of which debris flow is the most serious event $[5,6]$. In addition to common volcanic debris flow, there are various types of debris flow in the basin, which can be 
considered a "museum" of debris flow disasters. Due to the characteristics of climate and topography, glacial meltwater debris flow is the most common and serious mountain disaster along the Sichuan-Tibet railway. For example, the debris flow in Guxiang Gully has broken out on a large scale many times; the greatest flow occurred in 1953 and was equivalent to one-third of the flood flow of the Yangtze River, washing out 80 million cubic meters of accumulated volume in one event [7-9]. An ice lake that burst in Midui Gully resulted in a flood and debris flow in 1988 that completely destroyed more than $40 \mathrm{~km}$ of the Sichuan-Tibet highway [10-12]. Therefore, revealing the regularity of occurrence and the factors that influence the degree of hazard has considerable value in ensuring the safety of construction and operation of the Sichuan-Tibet railway. The main criteria of viscous debris flow and glacial debris flow are as follows: The debris flow with glacier activity in the gully can be called a glacial debris flow. The content of viscous particles in this kind of debris flow is small, and the gravity of debris flow is usually less than $15 \mathrm{kN} / \mathrm{m}^{3}$. Most of the viscous debris flows are caused by rainfall, the clay content is relatively large, and the debris flow gravity is usually greater than $15 \mathrm{kN} / \mathrm{m}^{3}$, which is more common in Southwest China (Yunnan and Sichuan).

Gradation is an important factor that controls the movement characteristics of debris flow and determines the degree of damage $[12,13]$. Previous research has shown that grain composition and particle size distribution can influence the energy transfer mechanism inside the debris flow, producing differences in the velocity and distance of movement between landslide rock and soils with different gradations. For example, the permeability coefficient is low when there are many fine particles in the debris flow, and the permeability coefficient is strongly negatively correlated with the particle curvature coefficient (CC) and the equivalent particle size (D20). In contrast, debris flow with more coarse particles has a larger internal friction angle but reduced cohesion. However, the acceleration and peak velocity of debris flow movement is positively correlated with the content of fine particles. Therefore, it is of considerable importance to study the grading characteristics for a better understanding of the occurrence mechanisms and movement characteristics of glacial debris flows $[5,14,15]$.

Rheological characteristics are important parameters in the hazard assessment of debris flows. There are many properties that can influence the rheological characteristics of debris flow, such as bulk density, viscosity, shear stress, and pore-fluid pressure, most of which are correlated with particle size distribution. Traditionally, studies on the relationship between rheological properties and the particle size distribution of debris flow are based on dividing the debris flow into viscous and dilute categories according to their slurry properties $[16,17]$. For example, Chen et al. [18] designed a model where the shear stress of debris flow on an erodible bed is a function of the solid shear stress, fluid shear stress, and volume fraction. Yang et al. [7] focused on the rheological parameters and calculation methods of a debris flow slurry using a Mooney formula and Krieger-Dougherty formula to calculate the stiffness coefficient of the slurry with high accuracy. Although various empirical formulas for different debris flows have been continually revised, the classical formula has some notable limitations. For example, the formula typically requires further optimization based on the relevant characteristics of the specific debris flow, and the formula's parameters also tend to be highly complex $[2,19,20]$.

To date, little research has been conducted on the characteristics of a glacial debris flow along the Sichuan-Tibet railway. Most of the studies have been numerical simulations or remote sensing research, resulting in a lack of direct experimental research on the glacial debris flow samples of the Sichuan-Tibet railway. In the present study, a field investigation was conducted along the Sichuan-Tibet railway, and 55 samples of glacial debris flow deposits were systematically analyzed in regard to their grading and rheological properties. These data will contribute to revealing the movement rules and disaster risk of a glacier debris flow along the Sichuan-Tibet railway. Therefore, this study has considerable theoretical and practical significance for ensuring the safety of both the construction and later operation of the Sichuan-Tibet railway.

\section{Materials and Methods}

2.1. Debris Fluid Sampling. The sampling site is located in Tibet, China, along the Sichuan-Tibet railway from Kangding to Linzhi (Figure 1). To accurately determine the grading pattern of glacier debris flows, a considerable amount of information gathering and investigation was conducted prior to field sampling. First, the location information of typical glacier debris flow gullies was roughly determined based on the planning route of the Sichuan-Tibet railway, historical information on debris flows along the Sichuan-Tibet highway, and remote sensing data. Firstly, according to the remote sensing data, combined with the topographic characteristics of debris flow gully, whether there is a glacier in the debris flow formation area is judged. Then, according to the field investigation, whether the gully has debris flow eruption trace, whether the debris flow accumulation body presents debris flow erosion characteristics, whether there are moraine object characteristics, and so forth, are also judged and comprehensively judge whether the gully is glacial debris flow. In addition, the sampling gullies where debris flow had erupted within 1-2 months were identified based on the collected information and field investigations of debris flow gullies along the Sichuan-Tibet railway. The sampling range of the debris flow gullies primarily included the areas of formation, circulation, and accumulation and the location with typical surface characteristics.

According to the law of debris flow movement and the code for the investigation of unfavorable geology in Railway Engineering (2012), the typical solid materials of debris flow primarily consisted of clay, silt, gravel, block stone, and boulder, whereas the major solid materials of water rock flow are block stone, gravel, and gravel with a small amount of sand and silt. Moreover, the gravel content is highly variable and not necessarily representative of an area. Therefore, the primary basis for judging water rock flow or debris flow is 


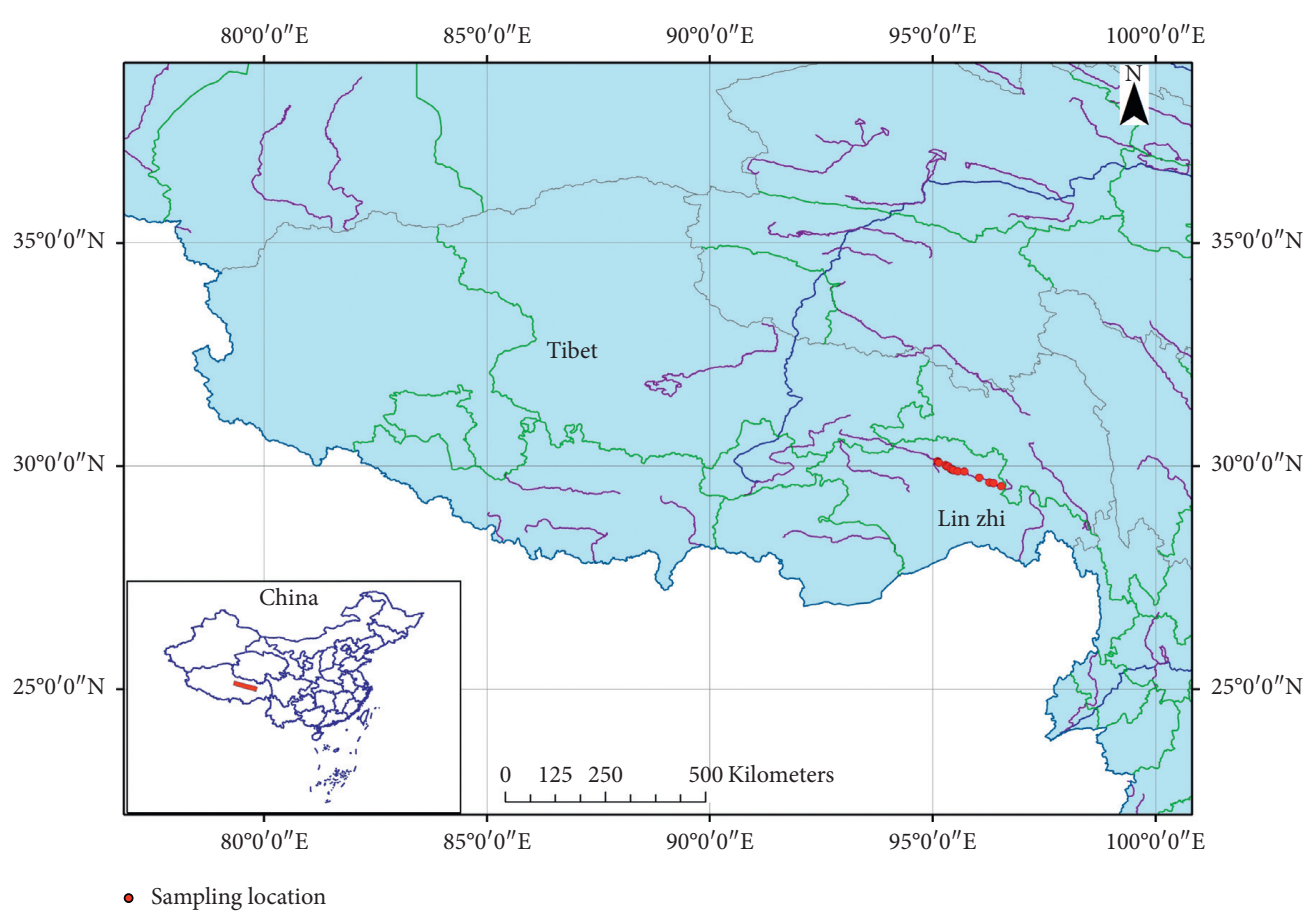

FIgURE 1: Sampling location.

the content of fine particles, and the sampling in this study was primarily focused on fine particles. Specifically, during sampling, the debris flow deposits that were disturbed more than $0.5 \mathrm{~m}$ above the ground surface were first removed, and then a shovel was used to excavate and collect the original soil (Figure 2). In total, 55 samples of glacial debris flow deposits along the Sichuan-Tibet railway were collected.

2.2. Particle Analysis. The particle analysis experiment was conducted in the debris flow simulation laboratory of the Chengdu Institute of Mountain Hazards and Environment, Ministry of Water Resources, Chinese Academy of Sciences. The particle screening was primarily conducted using an automatic screening instrument (FOCUCY-F-SD200, China), which includes an analysis screen, balance, shaker, and other auxiliary equipment and an electronic balance (with a capacity of $10 \mathrm{~kg}$ and an accuracy of $0.001 \mathrm{~g}$ ). The analysis sieves of the automatic screening instrument consisted of fine sieves $(2.0 \mathrm{~mm}, 1.0 \mathrm{~mm}, 0.5 \mathrm{~mm}, 0.25 \mathrm{~mm}$, and $0.075 \mathrm{~mm}$ ) and coarse sieves $(40 \mathrm{~mm}, 20 \mathrm{~mm}, 10 \mathrm{~mm}, 5 \mathrm{~mm}$, and $2 \mathrm{~mm}$ ). The automatic screening instrument can shake up, down, left, and right with an amplitude of $0.2-3 \mathrm{~mm}$ and a vibrational frequency of 3000 times $/ \mathrm{min}$. The process of the screening experiment is shown in Figure 3.

The specific test procedure was as follows:

(1) The mud and stone fluid was dried with an electric heater and forced-air drier, and a sample of approximately $3000 \mathrm{~g}$ was weighed out. The dried sample was sieved through a $2 \mathrm{~mm}$ sieve by shaking for $20 \mathrm{~min}$.

(2) The sample of particles exceeding $2 \mathrm{~mm}$ was placed on the coarse sieves, which were stacked according to size, and the sample of particles below $2 \mathrm{~mm}$ was placed on the fine sieves, which were also stacked according to size. After shaking for $15 \mathrm{~min}$, the mass of particles with each corresponding particle size was weighed.

(3) The quality of the sample obtained after sieving (the sum of the mass of the particles on the sieve trays and the mass of the chassis particles) was compared with the mass before sieving. If the difference was within $1 \%$, it was considered to be of adequate quality.

The percentage of the sample smaller than a certain particle size relative to the total mass of the sample was calculated as follows:

$$
X=\frac{m_{a}}{m_{b}}
$$

where $X$ is the percentage (\%) of the mass of the sample that is smaller than a given particle size in the total mass of the sample, $m_{a}$ is the mass of the sample smaller than a given particle size, and $m_{b}$ is the total mass of the sample.

To explore the particle characteristics of the typical glacial debris flow less than $1 \mathrm{~mm}$, a Malvern laser particle size analyzer (Mastersizer 3000e) was used to test the original debris flow. The basic principle of the laser particle sizer is that when the laser beam passes through the dispersed particle sample, different particles produce different intensities of scattered light, and the scattering pattern for the particle size is then calculated. The Malvern system consists of an optical platform, a sample disperser (accessory), and instrument software, which is controlled by a Mastersizer 3000. The Malvern laser particle sizer used in this experiment can measure particles from $1 \mu \mathrm{m}$ to 


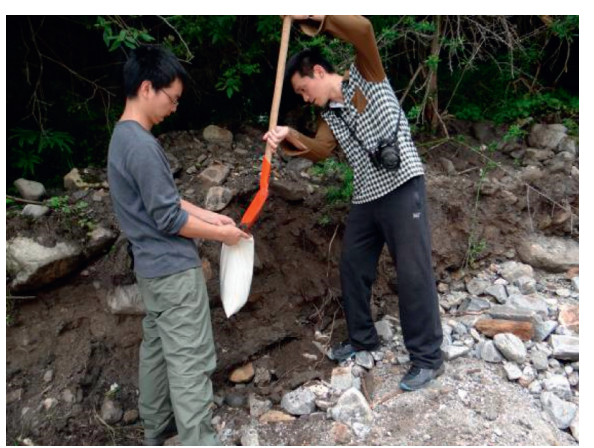

(a)

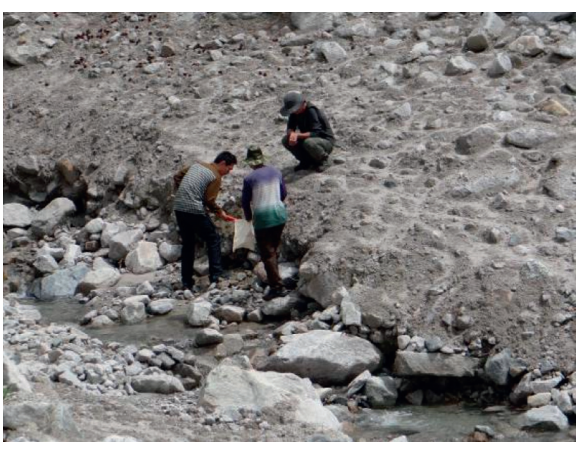

(c)

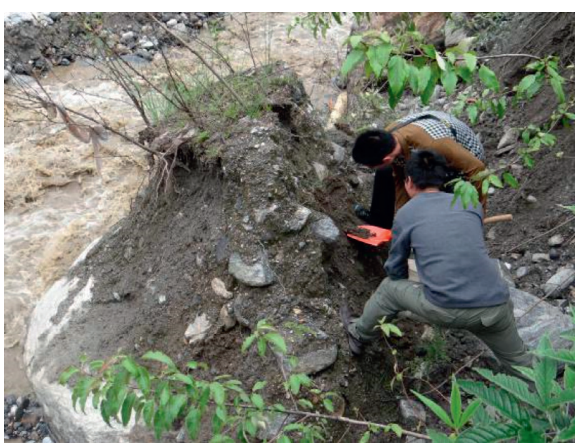

(b)

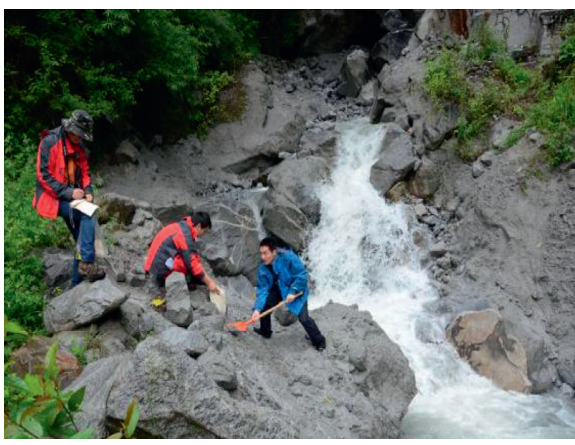

(d)

Figure 2: Site sampling process of glacial debris flow. (a) Qiemunongba. (b) Tianmogou. (c) Xingkongshanggou. (d) Dadanongba.

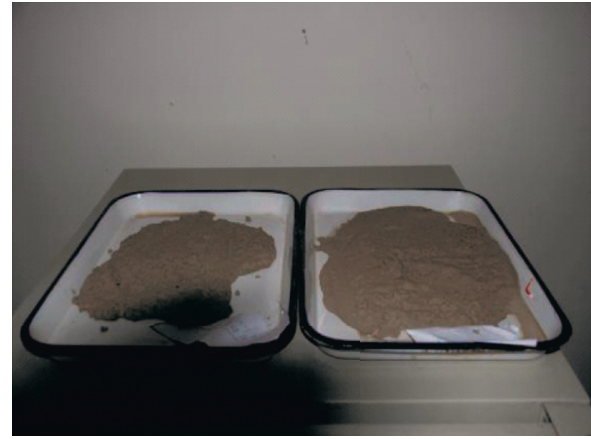

(a)

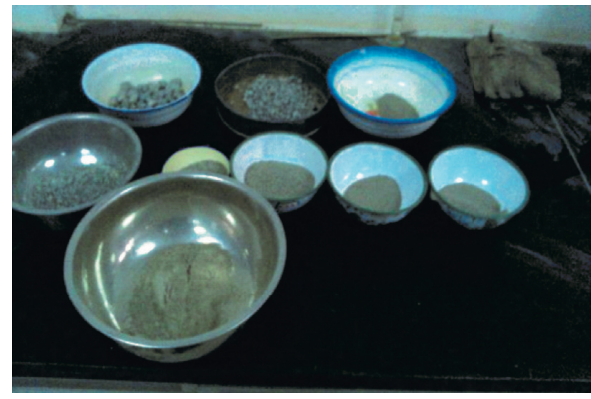

(c)

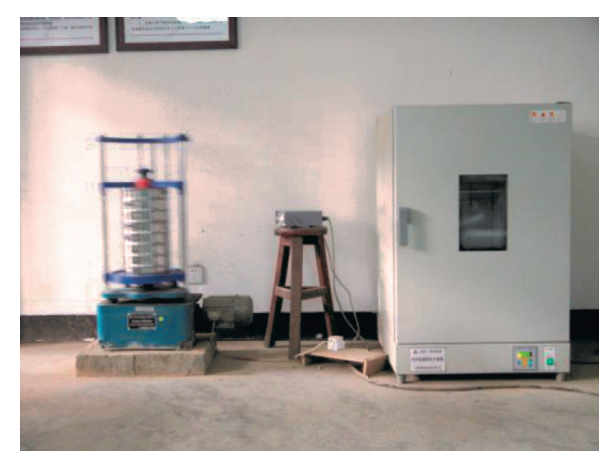

(b)

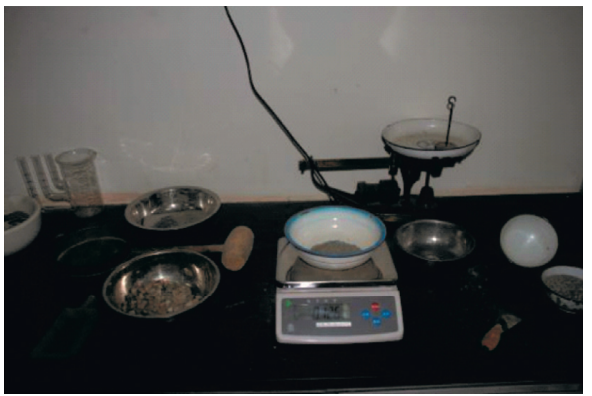

(d)

FIGURE 3: Screening test equipment. (a) Sample classification. (b) Drying and screening. (c) Collection of samples on screen. (d) Measurement.

$1000 \mu \mathrm{M}$. To facilitate the analysis, a series of characteristic particles including $1 \mu \mathrm{m}, 5 \mu \mathrm{m}, 10 \mu \mathrm{m}, 50 \mu \mathrm{m}, 100 \mu \mathrm{m}$, $250 \mu \mathrm{m}, 500 \mu \mathrm{m}$, and $1000 \mu \mathrm{m}$ were selected for analysis. In this experiment, particles less than $1 \mathrm{~mm}$ were screened out by the sieving method, and the Malvern particle analysis was then performed for the debris flow from different gullies. 
2.3. Rheological Experiment of Debris Flow. The instrument used in the rheological experiment was a Physica MCR 301 modular intelligent high-speed rheometer (Anton Paar, Germany), as shown in Figure 4(a). The test process was divided into the following stages. First, the particles with a diameter of $1 \mathrm{~mm}$ were removed with a round hole screen, and the debris flow slurries with different gravities were then arranged according to the experimental requirements. Different debris flow slurries were placed into the rheometer for loading and were read.

To eliminate experimental error, the loading scheme of the rheometer was designed into the experiment. Uniform acceleration loading was conducted with an acceleration range of 0 to $15(1 / \mathrm{S})$. The entire loading time is measured in seconds; $0-50 \mathrm{~s}$ is the stage of uniform acceleration loading, which is used to observe the stress state of the debris flow under a continuous increase in shear strain and to simulate the scene of initial debris flow. From 50 to $100 \mathrm{~s}$ is the stage of uniform deceleration loading, which is used to observe the stress characteristics of debris flow in the case of a gradual decrease in shear strain and to simulate the velocity of debris flow in the accumulation area. Finally, the working scene was gradually reduced and from 100 to $120 \mathrm{~s}$ is the acceleration state, which was used to simulate the related working scene of debris flow in a turbulent state (Figure 4(b)). The experimental process is shown in Figures 4(c) and 4(d).

\section{Results}

3.1. Gradation Characteristics of Glacier Debris Flow. The specific surface area, mineral properties, chemical composition, and physical properties of each particle are different, which affects the formation, movement, and structure of the debris flow fluid. Based on the screening results of the glacier debris, the particles can be divided into four different grades: particles smaller than $0.005 \mathrm{~mm}$ are clay, particles from 0.005 to $0.05 \mathrm{~mm}$ are powder, particles from 0.05 to $2 \mathrm{~mm}$ are sand, and particles from 2 to $40 \mathrm{~mm}$ are gravel. The sand can be further divided into four categories (coarse, medium, fine, and extremely fine), and the gravel can be divided into three categories (coarse, medium, and fine).

Figure 5(a) shows the grading curve of a glacial debris flow along part of the Sichuan-Tibet railway. The cumulative percent content of $0.5-10 \mathrm{~mm}$ glacial debris flow particles is significantly different in different valleys, which indicates that the sand and gravel content in the glacial debris flow along the Sichuan-Tibet railway is variable. Overall, the cumulative percent content of $0.05 \mathrm{~mm}$ particles is low in most glacial debris flow, and the percentage of $0.005 \mathrm{~mm}$ particles is even lower, indicating that the powder and clay contents are low.

An analysis of the grading data from 26 samples of glacial debris flow in Table 1 shows that the average percent gravel across samples is $37.8 \%$ with a standard deviation of $13.6 \%$, and the maximum and minimum values were $67.5 \%$ and $12.8 \%$, respectively. The grading data had a normal distribution $(p>0.05)$ as indicated by the normality test and distribution curve in Figure 6(a), which indicates that the sampling was representative. Figure 6(b) shows the frequency distribution of sand particles. The average content was $58 \%$ sand with a standard deviation of $13.6 \%$, and the maximum and minimum values were $79.9 \%$ and $22.9 \%$, respectively. As seen in the figure and as indicated by the normality test, the data in this size category were highly discrete and did not conform to a normal distribution $(p<0.05)$; most of the values fell between $45 \%$ and $55 \%$. The results indicate that there is a considerable variation in the sand content. Figure 6(c) shows the frequency distribution of powder. The average powder content was $3.7 \%$, the standard deviation was $2.3 \%$, and the maximum and minimum values were $9.99 \%$ and $0.54 \%$, respectively. As seen in the figure and indicated by the normality test, these data did not conform to a normal distribution $(p<0.05)$; most of the values were concentrated between $2 \%$ and $5.5 \%$. Figure $6(\mathrm{~d})$ shows the frequency distribution of the clay particles. The average clay content was $0.47 \%$, the standard deviation was $0.07 \%$, and the maximum and minimum values were $1.74 \%$ and 0 , respectively.

The different categories had the following particle size characteristics. The gravel was primarily composed of mineral debris and rock blocks. In the process of debris flow formation and circulation, its physical properties are the most stable, it does not absorb water, and it has a greater impact capacity. The primary components of the sand were coarse-grained primary minerals and fragments of rockforming minerals. During the formation of debris flow, the fine-grained slurry can form a mud film on the surface of the sand, causing the sand and the fine-grained slurry to form a relatively stable coarse-grained debris flow slurry, which has a substantial effect on the adhesion and drag reduction of the debris flow. The silt was primarily composed of primary and secondary minerals. After the formation of the debris flow, the silt and clay can form a relatively stable suspension slurry, providing buoyancy for the coarse particles. The clay was primarily composed of clay minerals (kaolinite, montmorillonite, etc.), iron, aluminum, manganese hydroxides, hydrous oxides, and so forth, which can form an extremely stable fine-grained slurry with structural and nonNewtonian characteristics. This analysis shows that the glacial debris flow has more coarse particles and less fine particles, such that the lack of clay content forms a debris flow that is less similar to the characteristics of the material it carries and more similar to the characteristics of the mountain torrents that move it. The flow velocity of the debris is more rapid than that of the conventional viscous debris flow, and the capacity for erosion is greater.

\subsection{Comparative Analysis of Gradations between Glacier} Debris Flow and Viscous Debris Flow. Figure 5(b) compares the grading curves of typical glacial debris flow and rainfall debris flow (Jiangjiagou debris flow). The figure shows that the content of fine particles (clay and silt) in the glacier debris flow is significantly lower than that in the Jiangjiagou debris flow. In particular, the difference in particle sizes smaller than $0.01 \mathrm{~mm}$ is the most obvious. The average percentage of the debris flow that is smaller than $0.01 \mathrm{~mm}$ in the Jiangjiagou flow is approximately $7 \%$, whereas that of the 


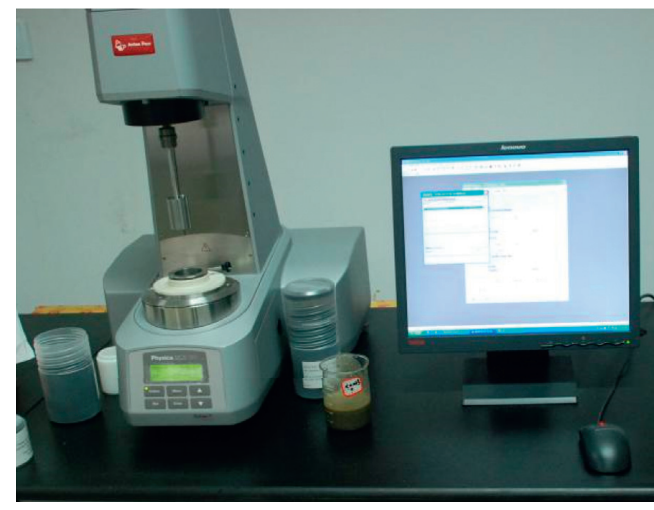

(a)

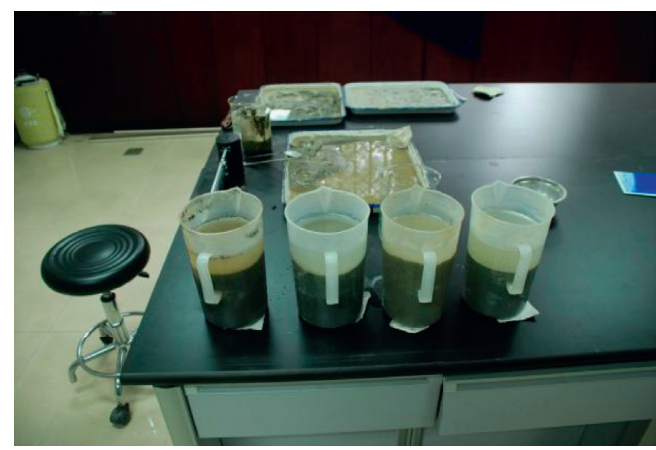

(c)

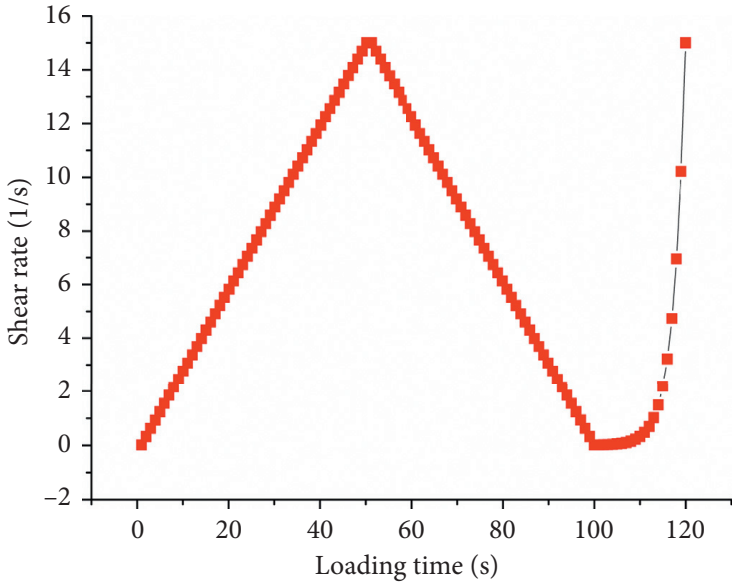

(b)

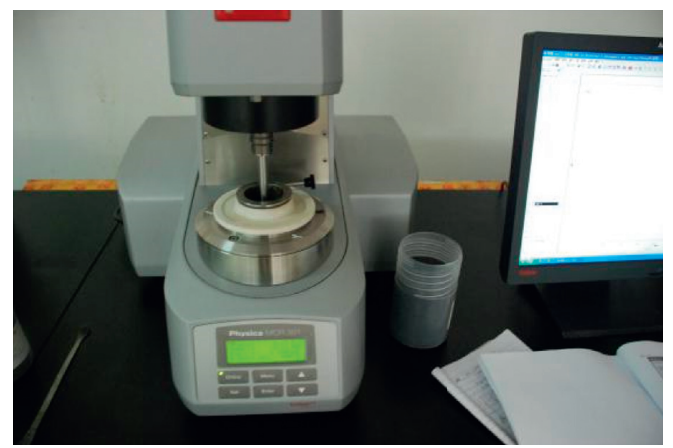

(d)

FIgURE 4: Rheological experiment instrument and process. (a) Physica MCR301. (b) Experimental loading process. (c) Rheological test sample. (d) Rheological experiment in progress.

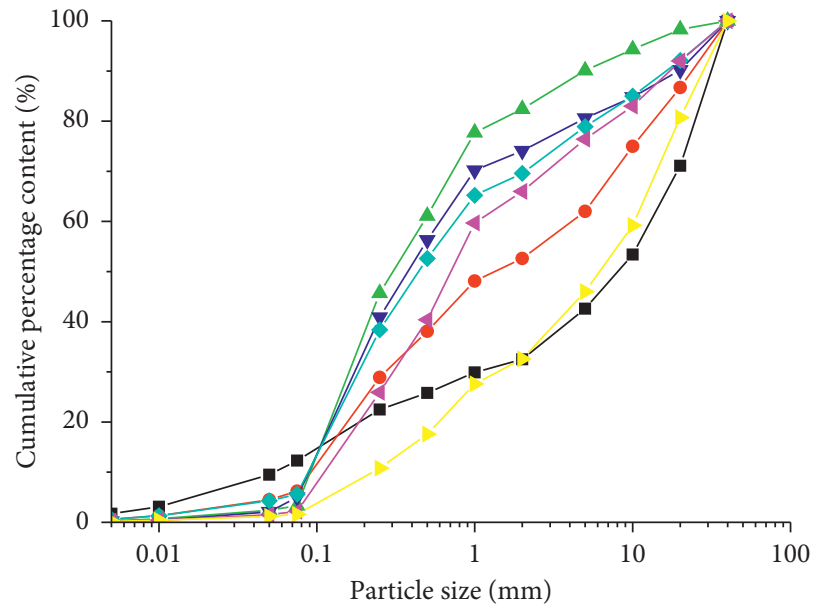

$\begin{array}{ll}-\square-\text { Jiurong Valley } & -\diamond-\text { Qiuzhu Nongba, } \\ -\bullet-\text { Jianmu Valley } & -<- \text { Guxiang Valley } \\ - \text { - }- \text { DaDa Valley } & \rightarrow \text { Naka Nongba } \\ -- \text { - Qimu Nongba } & \end{array}$

(a)

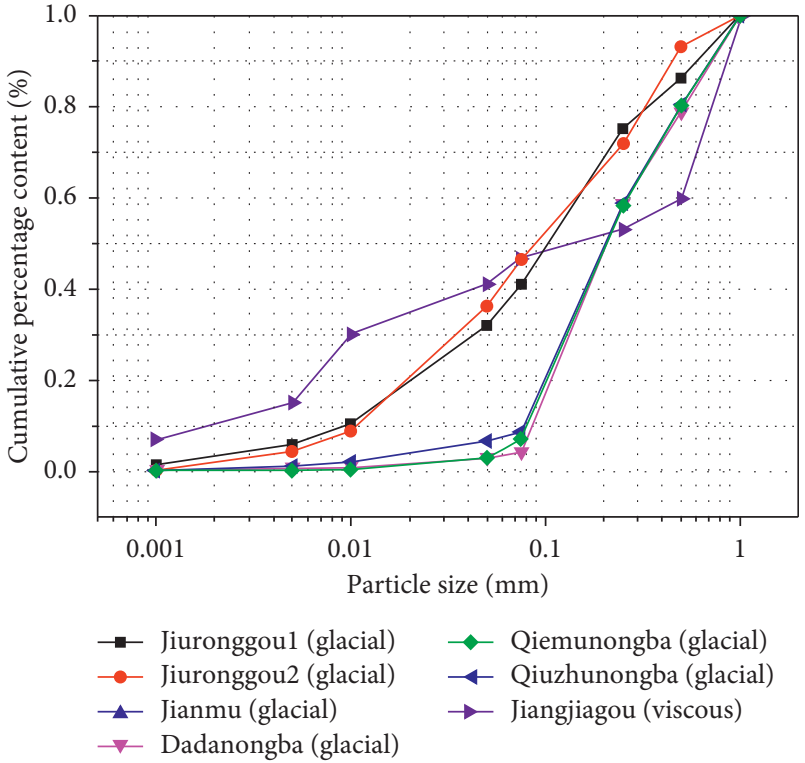

(b)

FIGURE 5: Grading curve of debris flow. (a) Grading curve of glacial debris flow. (b) Comparison of grading curves for glacial debris flow and viscous debris flow. 
TABLe 1: Glacier debris flow gradation data.

\begin{tabular}{|c|c|c|c|c|c|c|c|c|c|c|c|c|}
\hline \multirow{2}{*}{ Number } & \multicolumn{4}{|c|}{ Gravel (\%) } & \multicolumn{5}{|c|}{ Sand (\%) } & \multicolumn{2}{|c|}{ Powder (\%) } & \multirow{2}{*}{$\begin{array}{l}\text { Clay (\%) } \\
<0.005 \mathrm{~mm}\end{array}$} \\
\hline & $<40 \mathrm{~mm}$ & $<20 \mathrm{~mm}$ & $<10 \mathrm{~mm}$ & $<5 \mathrm{~mm}$ & $<2 \mathrm{~mm}$ & $<1 \mathrm{~mm}$ & $<0.50 \mathrm{~mm}$ & $<0.25 \mathrm{~mm}$ & $<0.075 \mathrm{~mm}$ & $<0.05 \mathrm{~mm}$ & $<0.01 \mathrm{~mm}$ & \\
\hline 1 & 100 & 71.1 & 53.4 & 42.6 & 32.5 & 29.9 & 25.8 & 22.5 & 12.3 & 9.5 & 3.1 & 1.7 \\
\hline 2 & 100 & 86.7 & 75 & 62 & 52.6 & 48.1 & 38.1 & 28.9 & 6.2 & 4.5 & 1.3 & 0.6 \\
\hline 3 & 100 & 98.3 & 94.3 & 90.1 & 82.4 & 77.7 & 61.1 & 45.7 & 3.3 & 2.4 & 0.7 & 0.3 \\
\hline 4 & 100 & 90.2 & 84.8 & 80.6 & 74.1 & 70.2 & 56.3 & 40.9 & 5 & 2.1 & 0.4 & 0.2 \\
\hline 5 & 100 & 92.1 & 85 & 78.9 & 69.6 & 65.2 & 52.6 & 38.4 & 5.6 & 4.3 & 1.3 & 0.6 \\
\hline 6 & 100 & 92 & 83 & 76.4 & 66 & 59.7 & 40.4 & 25.9 & 2.2 & 1.5 & 0.4 & 0.2 \\
\hline 7 & 100 & 80.7 & 59.2 & 46 & 32.6 & 27.6 & 17.6 & 10.8 & 1.6 & 1.2 & 0.4 & 0.2 \\
\hline 8 & 100 & 91.7 & 83.7 & 76.2 & 60.9 & 53.5 & 35.9 & 24 & 2.1 & 1.6 & 0.6 & 0.3 \\
\hline 9 & 100 & 85 & 76.6 & 66.6 & 56.2 & 43 & 32.1 & 15 & 5.7 & 3.9 & 1.3 & 0.6 \\
\hline 10 & 100 & 84.5 & 73.8 & 61 & 49.7 & 39.6 & 30.9 & 23.2 & 8.9 & 5.4 & 2.1 & 1.3 \\
\hline 11 & 100 & 100 & 96.2 & 92.5 & 87.2 & 74.4 & 47.9 & 31.9 & 11 & 7.5 & 1.6 & 0.4 \\
\hline 12 & 100 & 90 & 82.7 & 75.1 & 67 & 56.6 & 40.1 & 30.5 & 8.9 & 6.5 & 1 & 0.3 \\
\hline 13 & 100 & 77.5 & 73.9 & 69.2 & 63.3 & 54.2 & 36.8 & 26.7 & 6.7 & 4.9 & 1.4 & 0.6 \\
\hline 14 & 100 & 82.6 & 78.2 & 68.8 & 62.8 & 53.9 & 40.7 & 32.8 & 8.9 & 6.5 & 1.5 & 0.5 \\
\hline 15 & 100 & 100 & 94.3 & 80.5 & 70.4 & 55.1 & 38.6 & 32.3 & 13.5 & 10 & 0.6 & 0 \\
\hline 16 & 100 & 100 & 91.6 & 86.8 & 82 & 72.3 & 49.6 & 35.1 & 9.1 & 6.7 & 1.3 & 0.3 \\
\hline 17 & 100 & 73.5 & 68.4 & 53.9 & 46.5 & 38.5 & 26.9 & 19.9 & 6.1 & 4 & 0.5 & 0 \\
\hline 18 & 100 & 76.3 & 64.8 & 55.6 & 46.7 & 44.8 & 32.9 & 29 & 2.5 & 2.1 & 0.7 & 0.3 \\
\hline 19 & 100 & 87.1 & 82.1 & 77.9 & 70 & 67 & 48.5 & 42.5 & 4 & 3 & 0.8 & 0.4 \\
\hline 20 & 100 & 88.3 & 83.3 & 76.9 & 67.1 & 63.8 & 42.9 & 36.3 & 4.2 & 3.4 & 1.1 & 0.6 \\
\hline 21 & 100 & 92.7 & 83.8 & 73.3 & 59.5 & 54.6 & 19 & 12.6 & 1.5 & 0.6 & 0.1 & 0.1 \\
\hline 22 & 100 & 85.5 & 81.2 & 76.2 & 66.7 & 63.2 & 42.1 & 37.4 & 6 & 4.8 & 1.6 & 0.9 \\
\hline 23 & 100 & 90.3 & 81 & 73.1 & 62.6 & 59.1 & 39.3 & 34.1 & 6.1 & 4.6 & 1.3 & 0.7 \\
\hline 24 & 100 & 89.4 & 86.2 & 82.9 & 75.9 & 73 & 53 & 46.9 & 4.1 & 2.6 & 0.7 & 0.4 \\
\hline 25 & 100 & 74.3 & 67 & 61.6 & 54.1 & 51.3 & 32.3 & 27 & 4.8 & 3.8 & 1.1 & 0.6 \\
\hline 26 & 100 & 82.9 & 77.3 & 70.7 & 58.6 & 55.4 & 29.6 & 23.8 & 2 & 1.6 & 0.4 & 0.2 \\
\hline Std dev. & - & 7.8 & 10.4 & 13.3 & 15.0 & 14.3 & 11.3 & 9.7 & 4.9 & 4.2 & 3.0 & 1.5 \\
\hline
\end{tabular}

glacier debris flow is generally less than $5 \%$ with an average of $2.27 \%$. This indicates that the particle size content that is less than $0.01 \mathrm{~mm}$ in typical glacier debris flow is approximately $32.4 \%$ of that of the viscous debris flow. In debris flow samples from different sampling locations within the same debris flow gully, the grading characteristics of the debris flow are very similar, for example, the ancient township gully, Midui Gully, and Jiurong Gully.

To further explore the differences between the gradation of glacial debris flow and viscous debris flow, a double logarithmic coordinate diagram of debris flow gradation was constructed with $\lg \left(r / r_{\text {max }}\right)$ plotted on the abscissa and $\lg (p(r))$ plotted on the ordinate, where $r$ is the particle size of debris flow, $p(r)=m_{r} / m_{0}, m_{r}$ is the total mass of the particle size not greater than $r$, and $m_{0}$ is the total mass of particles. For the $y$-axis variable, the least square method was used to fit the aggregate size curve, and the slope was $\lambda$. Using $3-D=\lambda$, the fractal dimension $D$ of the aggregate grading was obtained. The fractal dimension of the particle grading for the different valleys is shown in Figure 7. The best fit equation for the fractal dimension calculation and the correlation coefficients of the different debris flow gradations are shown in Table 2 . The correlation coefficient $\left(R^{2}\right)$ was greater than 0.9 , which indicates that the equation has high reliability. The fractal dimension of glacial debris flow is between 1.9 and 2.4 with an average value of 2.166 , which is far less than the fractal dimension of Jiangjiagou (2.666, viscous debris flow). The larger the fractal dimension is, the more the fine particles are present; therefore, it can be concluded that there are fewer fine particles in the glacial debris flow. The results show that the average grain size of glacial debris flow ranges from 0.0943 to 0.2451 with an average of 0.2009 , which is much larger than the average grain size (0.0761) of Jiangjiagou (viscous debris flow).

3.3. Rheological Characteristics of Debris Flow. There are two typical rheological patterns of glacial debris flow. The first mode is shown in Figure 8(a). In this figure, the shear stress of debris flow increases rapidly with shear strain at low speed and then increases slowly and tends to be stable. Moreover, the shear stress occurs as a jump between $2 \sim 8 / \mathrm{s}$ of the shear stress rate. The reason for the jump may be related to coarse sand impacting the rotor of the rotating shaft. In the second mode, as shown in Figure 8(b), the shear stress increases with the shear strain and eventually stabilizes.

Debris flow gravity is an important factor that affects the rheology of debris flow. To study the rheological characteristics of the same debris flow under different gravities, the debris flow samples from Qiuzhuliba were selected, debris flow slurries of $13 \mathrm{kN} / \mathrm{m}^{3}, 15 \mathrm{kN} / \mathrm{m}^{3}, 18 \mathrm{kN} / \mathrm{m}^{3}$, and $20 \mathrm{kN} /$ $\mathrm{m}^{3}$ were configured, and the rheological experiments were conducted. The experimental results are shown in Figure 9(a). The figure shows that the shear stress of debris flow under $13 \mathrm{kN} / \mathrm{m}^{3}$ and $15 \mathrm{kN} / \mathrm{m}^{3}$ is small and can be ignored. The rheological characteristics of debris flow increase gradually under $18 \mathrm{kN} / \mathrm{m}^{3}$ gravity and initially increase and then decrease under $20 \mathrm{kN} / \mathrm{m}^{3}$ gravity. This 


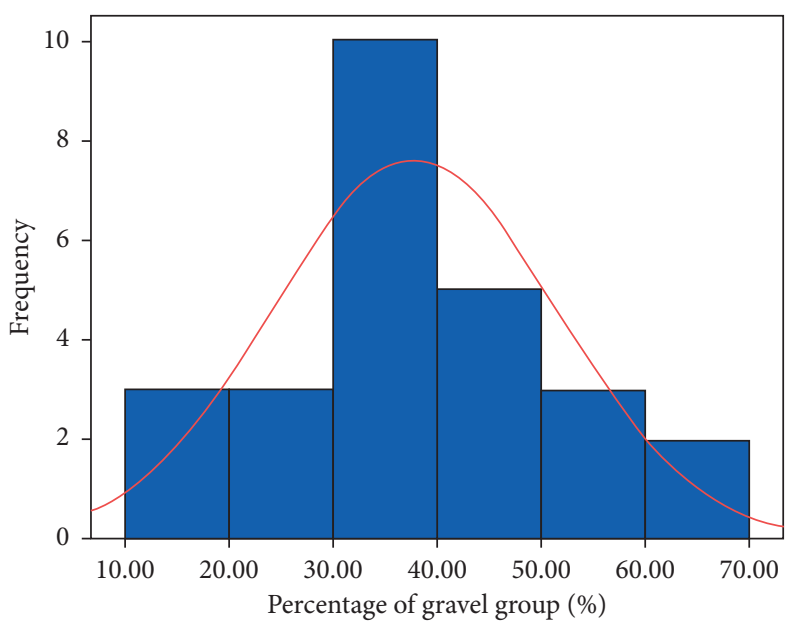

(a)

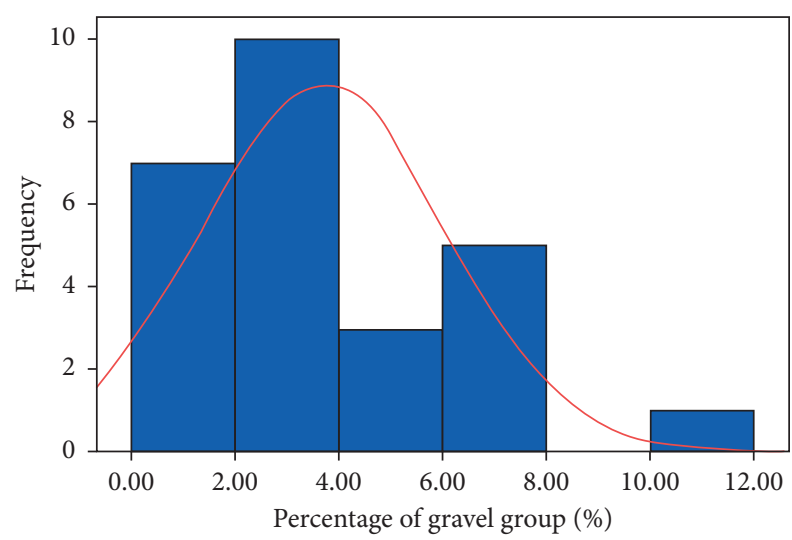

(c)

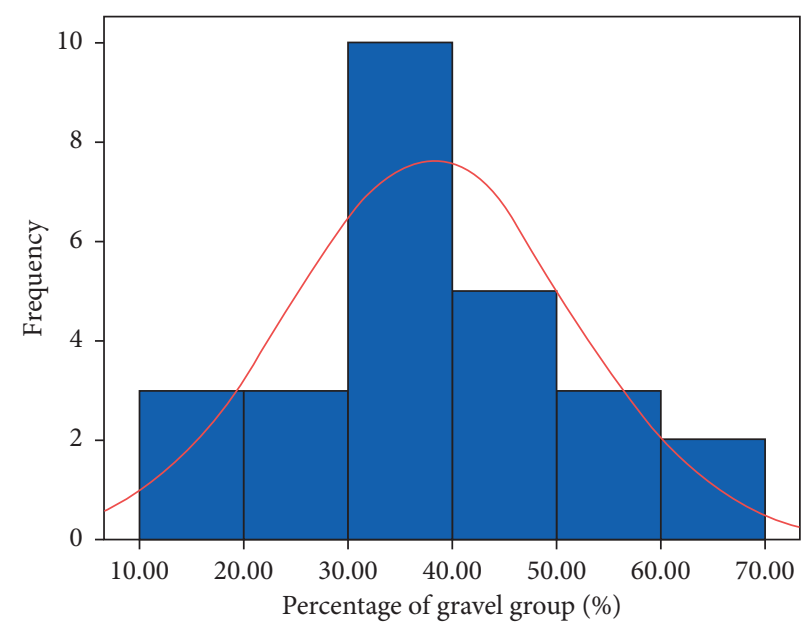

(b)

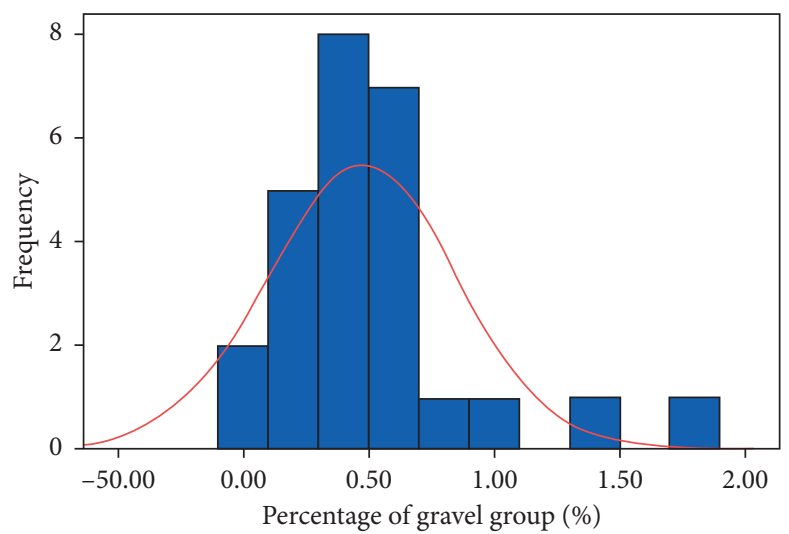

(d)

Figure 6: Frequency distributions for different categories of debris flow particle sizes. (a) Gravel. (b) Sand. (c) Powder. (d) Gravel.

pattern primarily occurs because after the shear rate of debris flow reaches a certain value, the protruding parts of particles in heavy and large debris flows show the same arrangement under the friction of the rheometer rotor, resulting in a decrease in friction. These results demonstrate that debris flow gravity has considerable influence on the rheological characteristics of debris flow. With the increase in debris flow gravity, the shear stress of debris flow under the same shear strain increases, which also explains why the flow velocity of debris is lower with greater gravity in the same debris flow gully.

To explore the difference in rheological characteristics between glacial debris flow and other viscous debris flow, the rheological curves of viscous debris flow and glacial debris flow are shown in Figure 9(b). Under the same shear rate, the shear stress of viscous debris flow was significantly greater than that of glacial debris flow, which reflects the greater fluidity of glacial debris flow.

\section{Discussion}

4.1. Gradation of Glacial Debris Flow and Its Difference from Viscous Debris Flow. The gradation composition of debris flow is an important part of the debris flow research.
Through the study of debris flow gradation, the characteristics of debris flow in a certain area can be obtained, such as debris flow composition, debris flow gravity, debris flow possible velocity prediction, debris flow erosion and deposition characteristics prediction, debris flow damage characteristics prediction, and debris flow control suggestions. Compared with other related studies, this study obtained the original samples of glacier debris flow along the Sichuan-Tibet railway for indoor analysis, which makes this study more targeted and data more reliable. The results show that the average contents of silt and clay are $3.7 \%$ and $0.47 \%$, respectively, and the rest are gravel and other large particles (Figure 6). Compared with the typical viscous debris flow, Jiangjiagou debris flow, it is found that the content of clay and silt in the typical glacial debris flow is much lower than that in the viscous debris flow (Figure 5(b)). The results show that the fractal dimension of glacier debris flow is much smaller than that of viscous debris flow, indicating that the average particle size of glacier debris flow is larger.

The possible reasons for this phenomenon are as follows: the differentiation of rocks can be divided into physical weathering, chemical weathering, and biological weathering. Due to the relatively cold climate and less biological activities in the glacier area of the Qinghai Tibet Plateau, chemical 


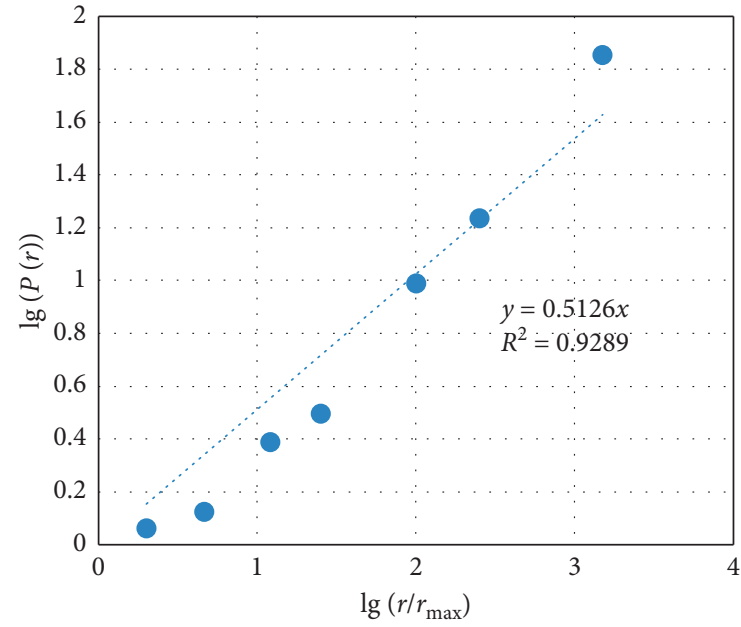

(a)

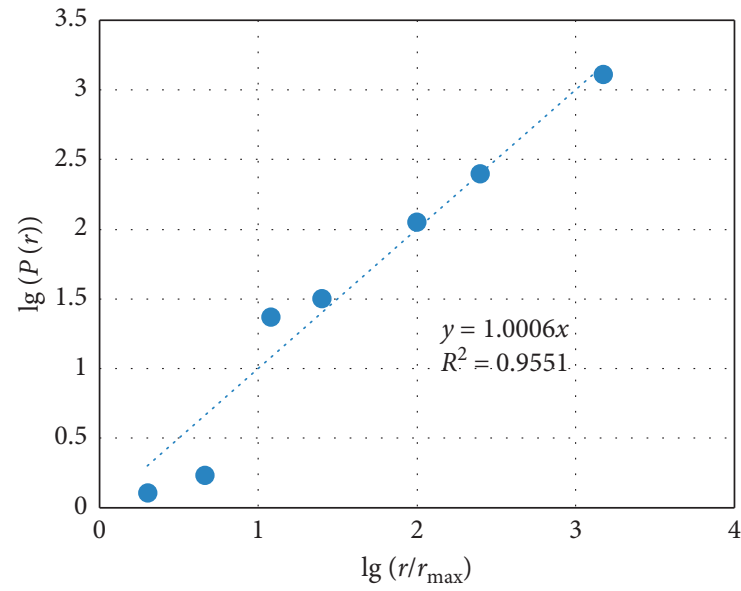

(c)

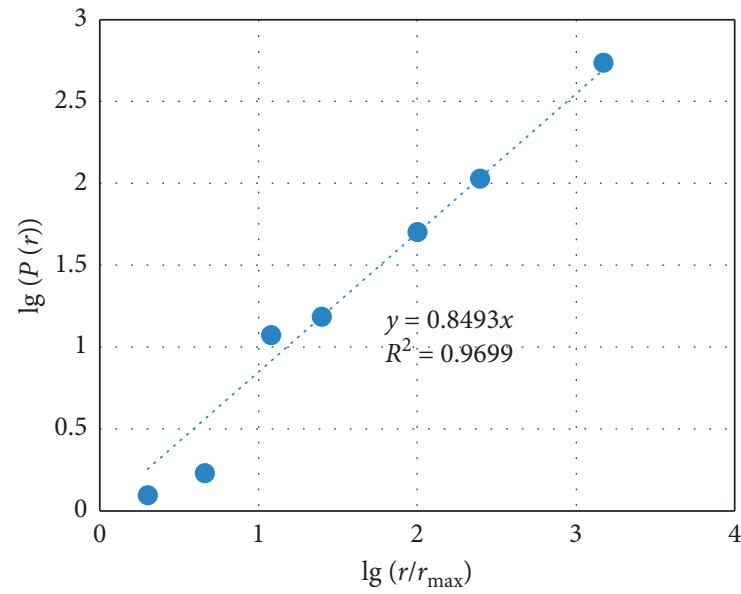

(e)

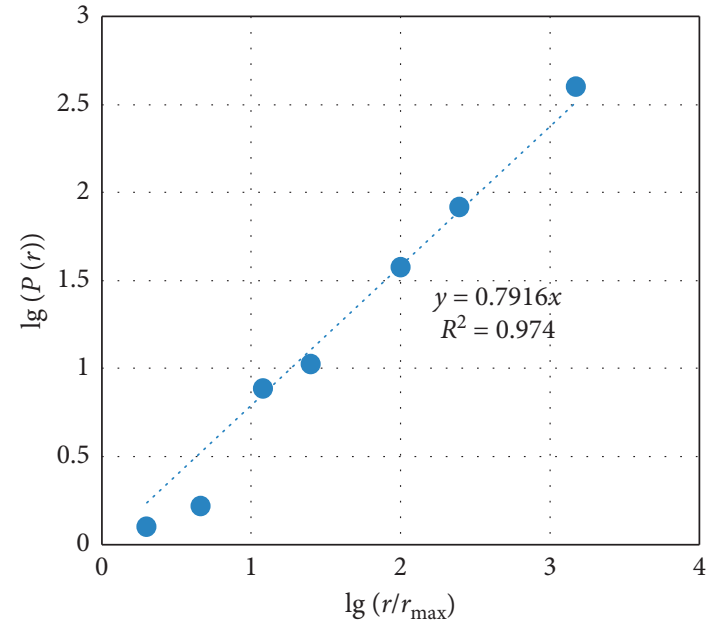

(b)

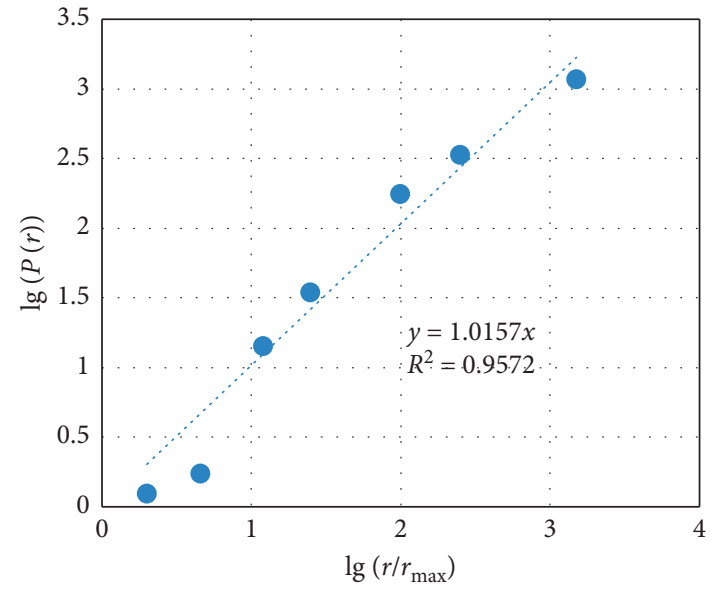

(d)

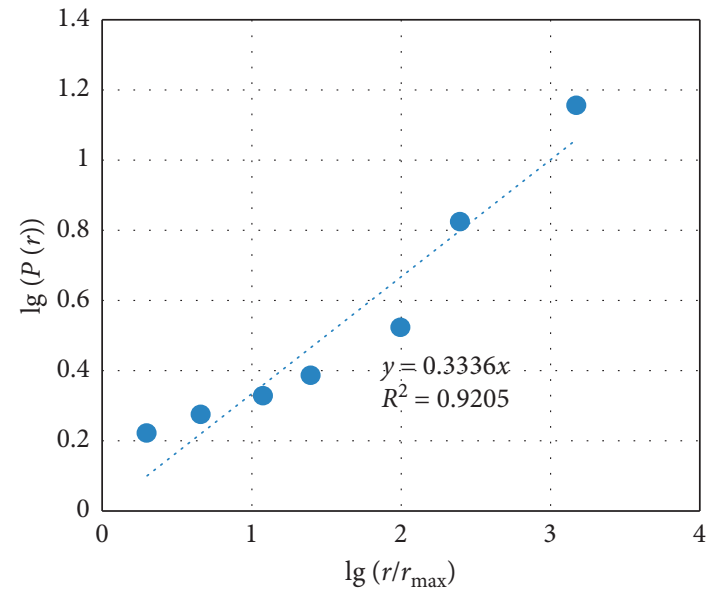

(f)

Figure 7: Fractal dimension scatterplots. (a) Jiuronggou. (b) Jianmugou. (c) Dadanongba. (d) Qiemunongba. (e) Qiuzhunongba. (f) Jiangjiagou.

differentiation and biological weathering are relatively small. And because the bedrock along the Sichuan-Tibet railway is primarily composed of granite gneiss, biotite hornblende quartz schist, biotite sheet, hornblende schist, and so forth, after weathering and the glacial cycle, the content of fine loose particles (clay and powder particles) formed from this 
TABLE 2: Comparison of fractal dimensions and geometric mean diameters.

\begin{tabular}{lcccc}
\hline Name of debris flow & Linear regression equation & $R^{2}$ & Fractal dimension & Geometric mean diameter \\
\hline Jiuronggou & $y=0.5126 x$ & 0.9298 & 2.4874 & 0.0943 \\
Jianmugou & $y=0.7916 x$ & 0.974 & 2.2084 & 0.2051 \\
Dadanongba & $y=1.0006 x$ & 0.9551 & 1.9994 & 0.2451 \\
Qiemunongba & $y=1.0157 x$ & 0.9572 & 1.9843 & 0.2389 \\
Qiuzhunongba & $y=0.8493 x$ & 0.9699 & 2.1507 & 0.2211 \\
Average value & - & - & 2.16604 & 0.2009 \\
Jiangjiagou & $y=0.3336 x$ & 0.9205 & 2.6664 & 0.0761 \\
\hline
\end{tabular}

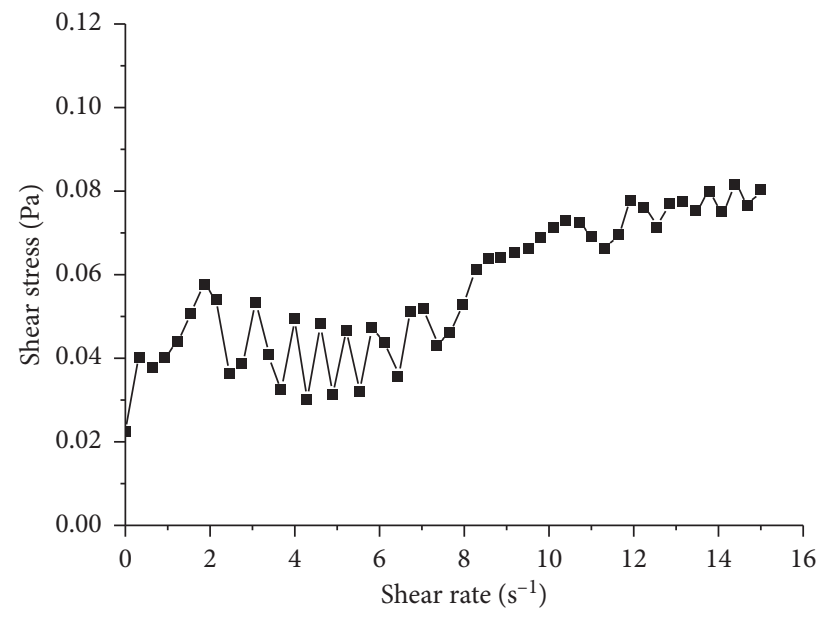

(a)

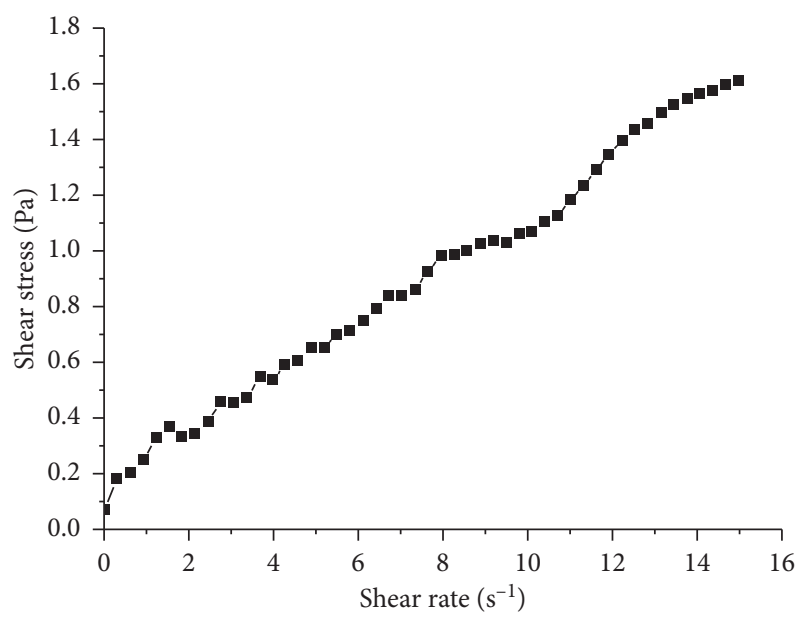

(b)

Figure 8: Rheological curves of debris flow. (a) Guxiang gully (bulk weight $13 \mathrm{kN} / \mathrm{m}^{3}$ ). (b) Qiuzhu Nong (bulk weight $18 \mathrm{kN} / \mathrm{m}^{3}$ ).

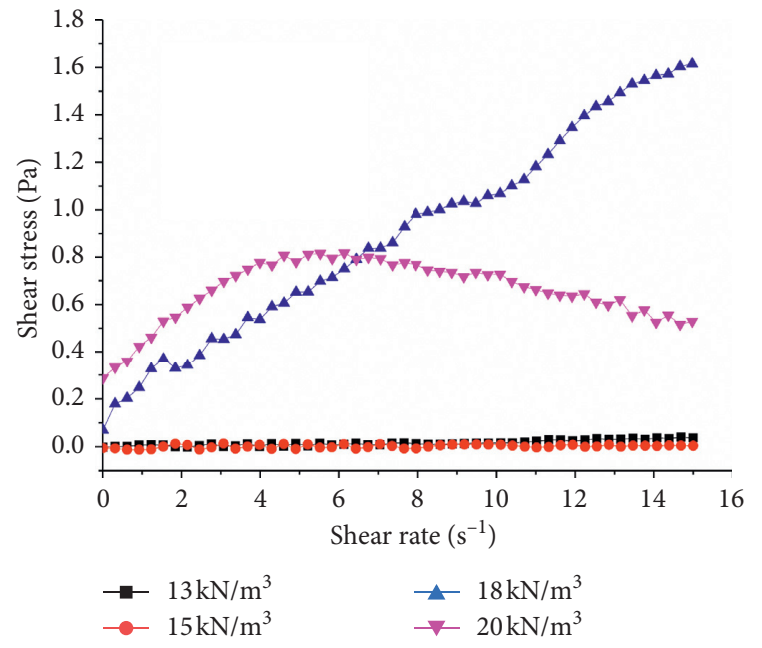

(a)

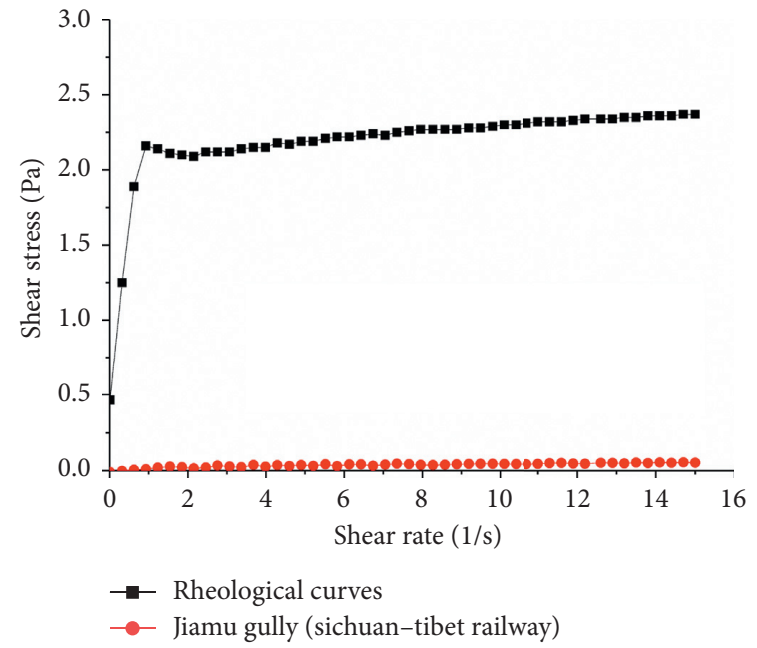

(b)

Figure 9: Comparison of different rheological models. (a) Rheological characteristics of debris flow with different bulk weights. (b) Comparison of the rheological curves of viscous debris flow with that of the Sichuan-Tibet railway.

bedrock is decreased such that coarse sand particles are primarily carried during the formation of the debris flow, rather than small particles.

Glacier debris flow has the characteristics of less fine particles, which determines that the mud is thinner and easier to form dilute debris flow. The characteristics of small fine particles enhance erosion, and the rarefied debris flow has stronger erosion characteristics. Therefore, in the design of debris flow prevention and control along the Sichuan-Tibet railway, it is necessary to deepen the buried 
depth of relevant drainage channels and sand bar bases to prevent erosion damage.

4.2. Rheological Characteristics. The rheological property of debris flow is one of the important characteristics of debris flow movement, which can directly reflect the magnitude of friction resistance in the process of debris flow movement. Through the rheological analysis of debris flow along the Sichuan-Tibet railway, it is found that there are two rheological states: laminar flow and turbulent flow. Through the analysis of the two rheological models of glacier debris flow, it is found that the two models correspond to the dynamic rheological model and turbulent rheological model, respectively. The two rheological models are as follows:

$$
\begin{aligned}
& \text { laminar flow model: } \tau=\tau_{0}+K\left(\frac{\mathrm{d} v_{c}}{\mathrm{~d} y}\right) \\
& \text { turbulant flow model: } \tau=\tau_{0}+\eta\left(\frac{\mathrm{d} v_{c}}{\mathrm{~d} y}\right)+\xi\left(\frac{\mathrm{d} v_{c}}{\mathrm{~d} y}\right)^{2},
\end{aligned}
$$

where $\tau$ is the shear stress of debris flow; $\tau_{0}$ is the initial static shear stress or yield stress of debris fluid; $\mathrm{d} v_{c} / \mathrm{d} y$ is the velocity gradient; $K$ and $\eta$ are the consistency and flow index, respectively; and $\xi$ is the dispersion coefficient.

When the gravity of debris flow is low, the movement of glacier debris flow presents a turbulent mode, and when the gravity is high, it presents a layer dynamic model. According to the analysis of debris flow gradation, the content of viscosity and fine particles of glacier debris flow is low, and the gravity is usually below $15 \mathrm{kN} / \mathrm{m}^{3}$. Therefore, glacier debris flow is mostly dilute debris flow, so its motion mode is mostly turbulent mode. In this mode, the movement of debris flow has strong jumping and destructiveness.

Compared with viscous debris flow, the shear stress of glacier debris flow is significantly smaller than that of viscous debris flow under the same gravity and shear rate, which indicates that glacier debris flow has smaller movement resistance. The main reason for this phenomenon is that the content of clay in Glacier debris flow is less, and the slurry forming debris flow is less. Most of the sand and stone particles are driven by water, and the overall friction force is small. The resistance to the relative movement of debris flow is relatively small. Through the topographic study, we can find that the glacier debris flow is mostly located in high mountains and valleys, and the gully slope is larger, so it contains more energy. Once the glacier debris flow breaks out, its movement speed will be far greater than that of viscous debris flow in the same state. Therefore, the protection standard should be improved to ensure the safety of the project.

\section{Conclusions}

The characteristics of a glacier debris flow along the Sichuan-Tibet Railway were systemically studied in regard to its gradation and rheological characteristics through field investigation and laboratory analysis. For the glacier debris flow along the Sichuan-Tibet railway, gravel and sand accounted for the largest proportion of particle gradation, the variability of which was high and the differences in particle size categories were significant. This finding indicates that the genesis of debris flow is complicated. Although the proportion of fine particles (clay and silt) was low, it plays an important role in determining the gradation characteristics of glacier debris flow. In this paper, the fractal dimension and geometric average size of debris flow are also analyzed and studied, and the gradation of glacier debris flow and viscous debris flow is compared from different angles. The content of fine particles in glacier debris flow was significantly lower than that of typical viscous debris flow, which is primarily determined by the characteristics of the organizing materials. It is suggested that the main reason for the small number of fine particles in Glacier debris flow may be due to the less biological and chemical differentiation.

The study on the rheological characteristics of glacier debris flow shows the change in the rheological curve of typical glacial melt cement stone flow had great variability and showed turbulent characteristics. Under the same gravity and shear rate, the stress of typical glacial debris flow was significantly less than that of viscous debris flow, whereas the variability of the stress was more significant. The low content of fine particles in glacial debris flow leads to the characteristics of low shear stress, which also leads to higher flow velocity and stronger breaking force. The present study provides a better understanding of movement rules and the disaster risk associated with glacier debris flow along the Sichuan-Tibet railway.

\section{Data Availability}

The data used to support the findings of this study are available from the corresponding author upon request.

\section{Conflicts of Interest}

The authors declare that there are no conflicts of interest regarding the publication of this paper.

\section{Acknowledgments}

The authors thank the Chinese Academy of Sciences for providing the experimental site and Dr. Tang Jun for his guidance. This paper was supported by the Sichuan Science and Technology Program (2020YFH0085), "Complete set technology and engineering application of medium and low speed maglev transportation system" (contract no. 2018$\mathrm{a} 01)$.

\section{References}

[1] L. A. McGuire and J. D. Pelletier, "Relationships between debris fan morphology and flow rheology for wet and dry flows on Earth and Mars: a numerical modeling investigation," Geomorphology, vol. 197, no. 3, pp. 145-155, 2013.

[2] D. M. Staley, J. A. Negri, J. W. Kean, J. L. Laber, A. C. Tillery, and A. M. Youberg, "Prediction of spatially explicit rainfall intensity-duration thresholds for post-fire debris-flow 
generation in the western United States," Geomorphology, vol. 287, no. 1, pp. 149-162, 2016.

[3] M. Zimmermann and W. Haeberli, "Climatic change and debris flow activity in high-mountain areas. a case study in the Swiss Alps," Catena Supplement, vol. 22, no. 1, pp. 59-72, 1992.

[4] H. Breien, F. V. De Blasio, A. Elverhøi, and K. Høeg, "Erosion and morphology of a debris flow caused by a glacial lake outburst flood, Western Norway," Landslides, vol. 5, no. 3, pp. 271-280, 2008.

[5] P. Cui, K. Hu, J. Zhuang, Y. Yang, and J. Zhang, "Prediction of debris-flow danger area by combining hydrological and inundation simulation methods," Journal of Mountain Science, vol. 8, no. 1, pp. 1-9, 2011.

[6] S. Liu and J. Zhang, "Experimental study on rheological and gradation characteristics of ice-cement-rock flow along Sichuan-Tibet Railway," China Railway, vol. 2, no. 5, pp. 101-106+113, 2019.

[7] H. Yang, K. Hu, and W. Fangqiang, "Study on the calculation method and expansibility of rheological parameters of debris flow slurry," Journal of Water Resources, vol. 11, no. 3, pp. 1338-1346, 2013.

[8] H. Peng, Y. Zhao, P. Cui, W. Zhang, X. Chen, and X. Chen, "Two-dimensional numerical model for debris flows in the Jiangjia Gully, Yunnan Province," Journal of Mountain Science, vol. 8, no. 6, pp. 757-766, 2011.

[9] H. Zhao, Y. You, and J. Liu, "Rheological characteristics analysis of debris flow," Science and Technology and Engineering, vol. 15, no. 27, pp. 120-126, 2015.

[10] Z. Hu, J. Zhang, X. Liu, K. Yang, and Z. Guo, "Experimental study on Influencing factors of rheological properties of debris flow slurry," Journal of Hydropower, vol. 33, no. 2, pp. 131-136, 2014.

[11] W. Suo, Study on the Effect of Particle Size Distribution on the Start-Up of Slag Debris Flow and its Disaster Mechanism, Chang'an University, Xian, China, 2019.

[12] X. Liu, P. Cui, F. Wang, and Y. Dong, "Study on the initiation mechanism of debris flow from engineering waste residue under different particle size gradations," Journal of Engineering Geology, vol. 26, no. 6, pp. 1593-1599, 2018.

[13] L. Zhang, Y. you, J. Liu, H. Sun, and D. Liu, "Experimental study on the influence of particle size distribution on uplift pressure of debris flow dam foundation," Journal of Rock Mechanics and Engineering, vol. 37, no. 1, pp. 190-198, 2018.

[14] Z. Chen, R. Wang, M. Hu, Z. Wang, and D. Xu, "Analysis of the influence of clay particle content on the initiation of debris flow in Jiangjiagou," Geotechnical Mechanics, vol. 31, no. 7, pp. 2197-2201, 2010.

[15] M. Jakob, S. Mcdougall, H. Weatherly, and N. Ripley, "Debrisflow simulations on Cheekye River, British Columbia," Landslides, vol. 10, no. 6, pp. 685-699, 2012.

[16] Y. Ripley, A Numerical Simulation Study on the Dynamic Characteristics of Debris Flow, Chongqing University, Chongqing, China, 2012.

[17] H. Sun, Y. You, and J.-F. Liu, "Experimental study on characteristics of trapping and regulating sediment with an open-type check dam in debris flow hazard mitigation," Journal of Mountain Science, vol. 15, no. 9, pp. 2001-2012, 2018.

[18] H. Chen, H. Li, Y. Wang, and B. Cheng, "A comprehensive assessment Approach for WaterSoil environmental risk during railway construction in ecological fragile region based on AHP and MEA," Sustainability, vol. 12, no. 19, p. 7910, 2020.
[19] Y. Wang, Q. Zhan, W. Han, and R. Zou, "Experimental study on stress constitutive relationship of viscous debris fluid," Journal of Natural Disasters, vol. 1, no. 2, pp. 64-70, 2003.

[20] G. Shi, B. Cheng, and A. Li, "A mathematical model for calculating the "Brittleness Ductility" drop coefficient of sandstone in mining zones," Discrete Dynamics in Nature and Society, vol. 2020, Article ID 2621672, 7 pages, 2020. 